$1 \quad$ Enhancing static-load-test identification of bridges using

\title{
dynamic data
}

\author{
Wen-Jun Cao ${ }^{1,2 *}$, Chan Ghee Koh ${ }^{1}$ and I. F. C. Smith ${ }^{2,3}$ \\ ${ }^{1}$ Department of Civil and Environmental Engineering, National University of Singapore, \\ 117576, Singapore \\ ${ }^{2}$ ETH Zurich, Future Cities Laboratory, Singapore-ETH Centre, \\ 138602, Singapore \\ ${ }^{3}$ Applied Computing and Mechanics Laboratory (IMAC), School of Architecture, Civil and \\ Environmental Engineering (ENAC), Swiss Federal Institute of Technology (EPFL), \\ CH-1015, Lausanne, Switzerland
}

Abstract: In situ measurements have the potential to provide valuable information about the safety and the condition of bridges through implementation of systemidentification methodology. A significant amount of research has focused on system identification using either dynamic or static measurements separately. Realizing the complementary relationship between static and dynamic measurements, traditional model updating methods adopt error functions to account for the residual between modeling and measured values for various types of measurements. Behavioral models may be inaccurate due to incomplete representation of modeling and measurement uncertainties. Furthermore, the normalization of error functions may bring additional uncertainty to the identification process. In this paper, an approach based on the model falsification method is proposed to combine both static and dynamic measurements with explicit consideration of both modeling and measurement uncertainties. A measurement selection strategy is also used to help detect abnormal measurements. The approach has been evaluated using a highway flyover bridge in Singapore. Dynamic

\footnotetext{
${ }^{*}$ Corresponding author.

E-mail address: caowenjun@u.nus.edu/wenjun.cao@arch.ethz.ch (W.-J. Cao); cgkoh@nus.edu.sg (C.G Koh); ian.smith@epfl.ch (I.F.C Smith)
} 
1 measurement data include natural frequencies and mode shapes whereas static

2 measurement data include inclinations, deflections and strains. By combining both

3 static and dynamic measurements, this approach leads to falsification of additional

4 model instances and obtains a more precise prediction of parameter values than

5 approaches which interpret static measurements only.

6 Keywords: System identification; parameter estimation; multi-response; finite element

7 method; static measurements; dynamic measurements

\section{Introduction}

Measurements obtained from sensors enable engineers to evaluate the condition

11 of existing civil infrastructure, thus providing valuable information for asset managers.

12 Realizing the importance of structural health monitoring, an increasing number of asset

13 managers require instrumentation and monitoring during and after construction.

14 A significant amount of research has focused on the determination of unknown 15 structural properties using data-interpretation techniques based on measurements. The 16 most widely used technique is residual minimization, also known as model calibration.

17 This approach aims to find the optimal parameter values that yields the best match with 18 the corresponding measurements [1-4]. The main drawback of this method is that it 19 either does not include uncertainties in modeling and measurements or it involves the 20 assumption that all uncertainties are zero-mean-Gaussian-distribution along with 21 enough measurement data to justify that such a statistical distribution is adequately 22 reflected in the data. Such assumptions are not compatible with most applications in 23 civil infrastructure because they do not recognize model bias and systematic uncertainty 24 introduced by epistemic uncertainties. 
1 Probabilistic model updating using Bayesian inference scheme dates from the 2 1990's. Prior knowledge of model parameters is updated by Bayesian condition 3 probability using measurements and inspection. Instead of looking for an optimal 4 solution, this approach estimates posterior probabilities of updated results. Many 5 applications can be found in the literature [5-8]. Extensions of the traditional Bayesian 6 approach include a covariance matrix to describe correlations of uncertainties for each 7 comparison point. This method is able to provide statistical characteristics of prediction 8 when systematic errors are adequately described. Nevertheless, risk exists when the 9 uncertainty dependency values are incorrectly estimated, and this may result in biased posterior probability density functions ( $p d f)$ of the parameters [9].

11 In contrast to the logic of looking for the "right" parameter values, the model12 falsification method follows the logic brought by Karl Popper that every scientific 13 theory can be tested and falsified, but never logically verified [10]. A multi-model 14 approach based on this logic was proposed by Raphael and Smith [11]. Specifically, 15 instead of looking for the "optimal" parameter values, a set of parameter values are 16 considered "acceptable" as long as they agree well with observations. Robert-Nicoud 17 et al. [12] further adopted threshold boundaries to quantify the effects of modeling 18 measurement errors. Goulet et al. [9] proposed a probabilistic extension, which is called 19 error-domain model falsification (EDMF). This method is able to provide robust 20 parameter identification without making assumptions on uncertainty correlations and it 21 is most useful when dealing with systematic uncertainties. This method was evaluated 22 for cases of existing bridges, such as the Langensand Bridge [13] and the Aarwangen 23 Bridge [14] in Switzerland, and the Grand-Mere Bridge [15] in Canada. It has also been 24 applied in wind engineering by Vernay et al. [16], optimal sensor placement by 25 Papadopoulou et al. [17] and leak detection in a fresh-water supply network by Moser 26 et al. [18]. 
1 In full-scale monitoring on existing bridges, information is usually obtained

2 through either dynamic or static tests. Vibration monitoring data has a wide range of 3 applications, e.g., structural identification [19-21], damage detection [22-26], 4 upgrading assessment [27-29] etc. Many applications can be found using ambient 5 vibration data [1, 30-31], free-vibration data [6,32] and forced-vibration data [32, 33]. 6 Among them, ambient vibration is the most popular due to its low cost and minimum 7 interruption of traffic. Global characteristics such as natural frequencies, mode shapes, 8 and modal damping directly relate to the physical properties such as stiffness, mass and 9 damping. In static tests, bridges are loaded with heavy trucks while sensors are installed 10 to obtain global information like deformations and inclinations and local information 11 like strains. Pasquier et.al [14] used load-test data to reduce the uncertainty related to 12 remaining-fatigue-life predictions. Ren et al. [34] used static displacements to update a 13 finite element model.

However, unexpected incidents are inevitable and uncontrollable in field tests, 15 including malfunctioning sensors, inaccessible sensor locations, poor connection 16 between sensor and data acquisition devices, etc. Therefore, the exploitation of the 17 measurements becomes a key issue when applying system identification.

With the presence of multiple types of measurements, the common residual19 minimization approach is to find the optimal parameter values which minimize the error 20 functions between the measured and numerical response. Sanayei et al. [35] subdivided 21 the error functions into the static flexibility-based error function, strain-based error 22 function and modal flexibility-based error functions to account for the residuals 23 between modeling and measured displacements, strains and modal displacements. 24 These error functions are combined together after they are normalized to ensure that the 25 contribution of the objective functions is not dependent on the unit chosen. Schlune et 26 al. [36] tested six objective functions with various normalization methods and studied 
1 their effects. The main disadvantage is that each objective function influences the

2 results of identification and modeling. Besides, measurement and modeling

3 uncertainties are seldom considered. The same applies to Bayesian model updating

4 where the relative weights given to the contributions of the mode shape vectors and

5 modal frequencies in the likelihood function significantly affect the results [37].

The original contributions of this paper are as follows. First, we propose an

7 approach to combine both static and dynamic measurements by exploiting a user-

8 friendly data-interpretation method called model falsification. Second, we present a

9 measurement selection strategy to systematically and progressively detect abnormal

10 measurements that need to be excluded from the falsification methodology. The

11 remainder of this paper is organized as follows. Section 2 contains an introduction of

12 the system-identification method using model falsification. The proposed approach

13 which combines both static and dynamic measurements with a measurement selection

14 strategy is explained in Section 3. Section 4 covers the application to a highway flyover

15 bridge in Singapore, followed by conclusions in Section 5.

\section{System identification through model falsification} $\left[\theta_{1}, \theta_{2}, \theta_{3}, \cdots, \theta_{n}\right]$, such as geometries, material characteristics and boundary conditions, using information provided by measurements $\mathbf{Y}=\left[y_{1}, y_{2}, y_{3}, \cdots, y_{m}\right]$. To describe the system, behavior models $\mathbf{g}(\boldsymbol{\theta})$ are built based on initial knowledge of the system and engineering judgement. Multiple model instances $\boldsymbol{\Omega}$ are generated based on several combinations of system property values $\boldsymbol{\theta}^{\boldsymbol{k}}=\left[\theta_{1}^{k}, \theta_{2}^{k}, \theta_{3}^{k}, \cdots, \theta_{n}^{k}\right]$, leading to prediction $g_{i}\left(\boldsymbol{\theta}^{\boldsymbol{k}}\right)$ corresponding to measurement $y_{i}$ for $i=1,2, \ldots, \mathrm{m}$. Denote $\boldsymbol{\theta}^{*}$ as the

24 true parameter values, the difference between the prediction obtained $g_{i}\left(\boldsymbol{\theta}^{*}\right)$ and the

25 modeling uncertainty $\mathbf{U}_{k, g_{i}}$ should be identical as the true value of $\mathcal{T}$. It is also equal to 
1 the difference between $y_{i}$ and the measurement uncertainty $\mathbf{U}_{y_{i}}$. See in Equation (1a).

2 By rearranging the equation, Equation (1b) is obtained by putting all uncertainties in

3 the right-hand side. The combined uncertainty is denoted as $\mathbf{U}_{c_{i}}$.

$$
\begin{gathered}
g_{i}\left(\boldsymbol{\theta}^{*}\right) \pm \boldsymbol{U}_{k, g_{i}}=\mathcal{T}=y_{i} \pm \boldsymbol{U}_{y_{i}} \\
g_{i}\left(\boldsymbol{\theta}^{*}\right)-y_{i}=\boldsymbol{U}_{c_{i}}=\mp \boldsymbol{U}_{k, g_{i}} \pm \boldsymbol{U}_{y_{i}}
\end{gathered}
$$

Based on the error-domain-model-falsification approach (EDMF) $[9,13]$, if the

5 difference between model predictions and measurements falls inside the threshold

6 boundaries $\left\{u_{\text {low }, i}, u_{\text {high }, i}\right\}$, the corresponding instance is considered a candidate model.

7 Otherwise, it is falsified. The threshold boundaries are defined with a $m$-dimensional

8 hyper-rectangular domain that has a probability larger than or equal to a confidence

9 level $\phi$. The confidence level $\phi$ is adjusted using the Šídák correction to account for

10 using multiple measurements to do falsification simultaneously [9]. The adjusted

11 confidence level $\phi^{1 / m}$ is calculated through Eq. (1), where $f_{\mathbf{U}_{c_{i}}}\left(u_{c_{i}}\right)$ is the probability

12 density function of $\mathbf{U}_{c_{i}}$. $\phi$ is commonly set to 0.95 in civil engineering [9].

$$
\phi^{1 / m}=\int_{u_{\text {low }, i}}^{u_{\text {high }, i}} f_{U_{c_{i}}}\left(u_{c_{i}}\right) d u_{c_{i}}, \forall i \in\{1, \cdots m\}
$$

\section{Combination of dynamic and static measurements}

To obtain more precise predictions of parameter values, several types of measurements are often needed. The mass distribution and material stiffness of bridges

17 are normally the unknown parameters in the identification process. The utilization of dynamic properties (e.g., natural frequencies, mode shapes and damping ratios) is not 
enough to identify these parameters because mass and stiffness can be changed by the

2 same ratio while still providing the same eigensolutions. On the other hand, measured

3 changes in deflections, strains and inclinations are dependent on stiffness and

4 independent on mass distribution. Thus, static and dynamic measurements have the

5 potential to complement each other.

In EDMF, a model instance is either accepted as a candidate model or rejected as

7 a falsified model. Regardless of the number of measurements used, a model instance is

8 falsified when it is not consistent with at least one measurement. The risk that potential

9 candidate models are wrongly falsified tends to be high, especially when there is doubt

10 related to the quality of measurements. This can further lead to the bias parameter value

11 sets and, as a consequence, bias predictions.

12 Given the importance of the precision of measurements, it is essential to select 13 good measurements to do system identification. Within the same type of measurements, 14 Sanayei et al. [35] performed data quality analysis to assess the accuracy and reliability 15 of the measured data. Noisiest measurements were eliminated from the measured data 16 set based on the level of signal-to-noise ratio. Among eight load cases, $60 \%$ of 17 displacements, $87.5 \%$ of inclinations and $65.6 \%$ of strains finally passed the data 18 quality analysis. The average values of these three sets of tests were used in the 19 subsequent process. Between different types of static measurements, Pasquier et al. [38] 20 detected the erroneous measurements by carrying out sensitivity analyses of the 21 diagnostics to single measurement removal from the data set. The diagnostics used is 22 the number of candidate models. If the result showed a high sensitivity to a specific 23 measured data, this data was removed from the data set.

24 The goal of the measurement selection strategy that is proposed in this paper is to 25 use high-quality measurements to detect abnormal data in measurements. In this paper, 
1 modal properties obtained through dynamic measurements are used to detect abnormal

2 strain-gauge data.

3 When identifying global structural properties such as Young's modulus of 4 concrete and beam density, modal properties are usually considered to be more useful than local static measurements such as strains. This is because strains are more sensitive to the response in their vicinity while modal characteristics are related to the global response of structure. Another reason is that the installation of strain gauges on the undersurface of concrete bridges is more complicated than the installation of accelerometers on the deck. The quality of installation will directly affect the measurement results obtained.

In this approach, it is important to make sure that the dynamic characteristics are accurate as they are used to detect abnormal static measurements and determine the confidence level in the measured data. Here, we use two methods of modal analysis and also two types of vibration data (free-vibration data due to impulsive force and ambient vibration data) to obtain the modal properties.

The logic of the proposed measurement selection strategy is consistent with the model falsification concept. A measurement is considered not abnormal until more information is introduced. The information refers to the consistency of identified 19 parameter ranges with the more precise measurements. The process is shown in Figure 20 1. During the process, model falsification is performed iteratively.

The initial parameter set $\theta$ is chosen using initial knowledge (design drawings 22 and/or on-site inspection). The modeling and measurement uncertainties $\mathrm{U}_{g}, \mathrm{U}_{y}$ are 23 quantified using sensor knowledge, previously estimated uncertainties in the modeling 24 method (in this case, the finite element method) and engineering judgement. For 25 example, engineering judgement is used to ensure that modeling uncertainties are at 
1 least 5\% and finite element models typically over-estimate rigidity. A sensitivity study

2 then needs to be carried out to select parameters according to their relative importance

3 on model predictions.

4 In system identification, model simulations are usually time consuming. For 5 traditional sampling techniques such as grid-based sampling and Latin-hypercube 6 sampling techniques, the number of simulations increases exponentially with the 7 dimensionality of the parameter sets. To save computation time, the underlying 8 relationships between system parameters and responses are approximated using 9 advanced interpolating functions within surrogate models. A typical procedure is as 10 follows:

11 (1) generate a small set of parameters and calculate their responses through finite 12 element analysis

13 (2) find the optimal surrogate models that best fit the data. Cross-validation is used 14 to check whether the surrogate models are accurate enough.

15 (3) expand the parameter set to the whole set $\mathbf{X}$, and use surrogate models to 16 predict their responses $\widehat{\boldsymbol{g}}$.

17 In the second step, the measurement set is divided into static set $\mathbf{Y}_{s}=$ $18\left[y_{s, 1}, y_{s, 2}, \cdots, y_{s, n_{s}}\right]$ and dynamic set $\mathbf{Y}_{d}=\left[y_{d, 1}, y_{d, 1}, \cdots, y_{d, n_{d}}\right]$. The corresponding 19 modeling and measurement uncertainties are $\boldsymbol{U}_{s, \hat{g}}, \boldsymbol{U}_{s, y}, \boldsymbol{U}_{d, \hat{g}}, \boldsymbol{U}_{d, y}$. Two model 20 falsifications are carried out to find the candidate model sets $C M S_{s}$ and $C M S_{d}$ using $\mathbf{Y}_{S}$ 21 and $\mathbf{Y}_{d}$ separately.

If the identified parameter ranges $\left(\boldsymbol{\theta}_{S}, \boldsymbol{\theta}_{d}\right)$ deviate sufficiently from each other, we 23 consider that there is at least one abnormal measurement in $\mathbf{Y}_{s}$. Otherwise, it is assumed 24 that no abnormality is present, in which case all measurements should be used to 
1 perform the final falsification. Notice that what constitutes a "sufficient" deviation for

2 a measurement to be considered abnormal is a subjective judgement. In real

3 applications, the information is embedded in measurement uncertainties [39]. It is not

4 easy to identify this information based only on the knowledge provided by field tests.

5 Nevertheless, with the help of error domain model falsification, the measurement

6 uncertainties have been explicitly estimated. In this paper, we define that for each

7 parameter $\theta_{i}$, if the distance $d_{\theta_{i}}$ between identified parameters $\theta_{i, s}$ and $\theta_{i, d}$ is more

8 than $\alpha=10 \%$ of the initial range $R_{\theta_{i}}$, there exists abnormal static measurements. The

9 value of $\alpha$ is based on engineering judgement and may vary for other applications and

10 various confidence levels of measurements.

11 When measurement abnormality is detected, the measurement $y_{s, k}$ which falsifies

12 the largest amount of model instances $r_{k}$ of $C M S_{d}$ is removed from $\mathbf{Y}_{s}$. Then, a model

13 falsification is performed using the updated $\mathbf{Y}_{s}$ to obtain the new candidate model set.

14 Several iterations may be needed to locate all the abnormal measurements. After all 15 abnormal measurements are removed, both static and dynamic measurements are 16 combined together $\mathbf{Y}=\left[\mathbf{Y}_{s}, \mathbf{Y}_{d}\right]$ to perform the last round of model falsification. It is 17 possible that the candidate model set $C M S_{f}$ is empty, and this may be due to several 18 reasons including inappropriate assumptions in modeling and bad engineering 19 judgement regarding uncertainties. At this point, an iterative process involves 20 consideration of possible reasons and verification through activities such as new 21 measurements and on-site inspection. A framework to address this task has been 22 proposed by Pasquier [38] and is not explained in this paper. The final candidate model 23 set is denoted as $C M S_{f}=\left[\boldsymbol{\theta}_{f}, \widehat{\boldsymbol{g}}_{f}\right]$.

\section{4. Case study}


1 The case study involves a single-span concrete bridge for a highway flyover in

2 Singapore, shown in Figure 2. The bridge is $32 \mathrm{~m}$ in length, $16 \mathrm{~m}$ in width, and is

3 supported at each end by four bearings. The superstructure consists of four prestressed

4 concrete beams and a $220 \mathrm{~mm}$-thick concrete slab. The bridge consists of 3 lanes.

5 During the tests, Lane 1 was open to traffic while Lane 2 and Lane 3 were closed to

6 traffic and used for testing.

\section{$7 \quad 4.1$ Static test}

8 In the static test, six trucks of approximately $32 \mathrm{t}$ each are parked on the bridge as 9 shown in Figure 3(a). Electronic levels (Federal Electronic Level Gage Head, Model: 10 EGH-02013W2Z) and digital readout (Mahr Amplifier model no. 832F) are installed at 11 both ends of the bridge to measure inclinations (In1, In2). The deflections at four 12 locations (P1 P4) are measured by prisms installed at the bottom of the beams and a 13 laser tracker (FARO Vantage laser tracker) positioned on the road below the bridge.

14 Unlike other static sensors, strain gauges (TML PL-120-11-3LT, gauge length: $120 \mathrm{~mm}$ ) were installed 24 hours before the test. The installation needed pre-qualified 16 operators on an aerial work platform and this required traffic closure below the bridge.

17 The installation process was impaired by the poor quality of adhesive and the lack of 18 experience of the workers. Only 8 strain gauges instead of 14 (as planned) were 19 installed due to time constraints. The configuration of the locations of sensors is shown 20 in Figure 3.

\section{$21 \quad 4.2$ Free vibration test}

To identify the dynamic characteristics of this highway flyover, free-vibration 23 tests were conducted by moving trucks. Accelerometers (PCB 393B12, sensitivity: $2410 \mathrm{~V} / \mathrm{g}$ ) including eight vertical accelerometers (A1-A2, B1-B3, C1, C3-C4) and two 25 horizontal accelerometers (A3, C2) are installed on the surface of the concrete deck 
1 along both sides of the flyover; the configuration is shown in Figure 3. A1-A3 and B1-

2 B3 are connected to DEWE-511 data acquisition system, and C1-C4 are connected to

3 CoCo-80 handheld data acquisition system (sampling rate 1024Hz).

4 In order to obtain the free vibration response of the bridge, eight tests are carried 5 out to generate the impulsive force (Table 1). 32-ton trucks move along the bridge from

6 the east end to the west end at two speeds; the slow speed is approximately $20 \mathrm{~km} / \mathrm{h}$ and

7 the fast speed is approximately $40 \mathrm{~km} / \mathrm{h}$. In test 5 and test 6 , a rubber speed hump

$8(900 \mathrm{~mm} \times 500 \mathrm{~mm} \times 50 \mathrm{~mm})$ is installed on the surface of the designated lane to help

9 increase the excitation.

10 The Fast Fourier Transform (FFT) is used on the 10s free vibration acceleration11 time data to give a preliminary evaluation of the vibration properties of the bridge. The 12 resolution of FFT is $0.1 \mathrm{~Hz}$. Figure 4 shows field-test photos, accelerometer signals and 13 natural frequencies. The mean values of natural frequencies obtained are shown in 14 Table 2.

\subsection{Ambient vibration test}

In the ambient vibration test, the sensor configuration is the same as that of the 17 free vibration tests. Measurement is recorded during a period of 15 minutes when no 18 truck is running on Lane 2 and Lane 3 while Lane 1 remains open but with only sporadic 19 vehicles passing through. The modal properties are obtained using the stochastic 20 subspace identification method with unweighted principle component (SSI-UPC). The 21 stabilization diagrams are shown in Figure 5.

Four modes have been identified and the corresponding standard deviation of 23 natural frequencies are shown in Table 3. Mode 1 is the first vertical bending mode, 24 and Mode 2 is the torsional mode. Because all sensors are installed outside the vehicle 25 lanes near the two sides of the bridge, and no sensor is placed on the road surface 
1 between the two sides of the bridge to capture the mode shape. The mode shape

2 obtained in Mode 3 is similar to that of Mode 1. Based on the knowledge of dynamic

3 properties of a simply supported beam, it is easy to infer that Mode 3 is a lateral bending

4 mode, i.e. the bridge is bending in the horizontal direction. Mode 4 is the second vertical

5 bending. These measurement results are consistent with the numerical results obtained

6 by finite element analysis.

\section{$7 \quad 4.4$ System identification using both static and dynamic measurements}

The flyover is modeled in ANSYS [40] using a 3D solid element (element type "SOLID 185") shown in Figure 6. The mesh size is $0.2 \mathrm{~m}$. Boundary conditions are modeled using linear springs. Parameters to be identified include Young's modulus of concrete $(E)$, concrete density $(D)$, logarithm of bending stiffness of bearings (LogB), logarithm of vertical stiffness of bearings $(\operatorname{LogV})$ and $\operatorname{logarithm}$ of longitudinal stiffness of bearings $(\log L)$. In this case study, the design drawings we received are not the as-built reality and on-site measurement of real geometric dimensions was not allowed by the bridge owner due to time constraints related to the bridge closure. As a result, the concrete density $(D)$ is in fact an "equivalent density" accounting for the

17 geometric discrepancies. The logarithmic values of bearing stiffness are used because 18 the dynamic characteristics of the bridge are influenced by the orders of magnitude, 19 rather than the precise bearing stiffness values, based on parametric study of the finite 20 element model.

The initial ranges of all parameter values are defined based on engineering experience and information obtained from drawings, as shown in Table 4. Note that the

23 four girders are considered to have the same boundary conditions.

A sensitivity analysis is conducted to evaluate the relative importance of 
1 calculating the coefficient of determination $\left(R^{2}\right)$ for the quadratic correlation between

2 them. When $R^{2}$ is smaller than $5 \%$, the influence of parameter to the response can be

3 neglected. The results in Figure 7 show that the influences of material properties $(E$ and

$4 D$ ) are large on the dynamic response, while $E$ also influences greatly the static

5 responses. Among the bearing parameters, $\log \mathrm{V}$ is influential on deflections $(\mathrm{P} 1 \sim \mathrm{P} 4)$

6 and inclinations $(\operatorname{In} 1 \sim \operatorname{In} 2)$. Nearly all static responses are sensitive to $\operatorname{LogB}$. $\operatorname{LogL}$ is

7 the least influential parameter and is neglected by the $5 \% R^{2}$ threshold. Hence, all

8 parameters except $\log \mathrm{L}$ are selected to perform system identification.

9 Following the procedure of generating surrogate models, first, 1000 model 10 instances generated by the Latin-hypercube sampling technique [42] are calculated 11 using finite element analysis. Then, surrogate models are built based on Gaussian 12 process, resulting in $50^{4}=6,250,000$ samples ( 50 discrete values for every parameter).

13 In this study, uncertainties are described using uniform distributions and are 14 generally expressed as ratios (in percentage) of the parameter values. Uncertainties are 15 calculated as the product of the ratio and the corresponding predicted or measured 16 values. Sensor accuracies are taken from the respective product specifications. In 17 dynamic measurements, the uncertainty related to modal analysis is considered by 18 taking into account the results obtained by free vibrations and ambient vibrations. Other 19 uncertainty values are taken in according to $[13,38,43]$. The details are shown in Table $20 \quad 5$ and Table 6.

21 Modeling uncertainties are also introduced by adopting surrogate models. To 22 evaluate how accurately a surrogate model is able to predict values for unseen data, 23 generalization error was calculated using 4-fold cross validation $(k=4)$ in this case study. 24 The training data including parameters $\boldsymbol{\theta}_{t r}$ and responses $\mathbf{Y}_{t r}$ are randomly divided into 254 subsets. Each data subset is then used as a test set $S_{j}^{\text {test }}$ including $n$ pairs of 
1 parameters $\boldsymbol{\theta}_{j}^{\text {test }}$ and responses $\boldsymbol{y}_{j}^{\text {test }}$, with the remaining data acting as a training set

$2 S_{j}^{\text {train }}=\left\{\boldsymbol{\theta}_{j}^{\text {train }}, \boldsymbol{y}_{j}^{\text {train }}\right\}$. Surrogate models $\widehat{\boldsymbol{g}}$ are generated by the training set and are

3 used to predict the response of test data $\widehat{\boldsymbol{g}}\left(\boldsymbol{\theta}_{j}^{\text {test }}\right)$. The usual average test set error $\hat{\mu}_{i}$

4 and generalization error $\hat{\mu}$ are calculated following (3) and (4). The calculated surrogate

5 model uncertainties are shown in Table 7.

$$
\begin{gathered}
\hat{\mu}_{i}=\frac{1}{n} \sum_{i \in S_{j}^{t e s t}}\left|\widehat{\boldsymbol{g}}\left(\boldsymbol{\theta}_{j}^{\text {test }}\right)-\boldsymbol{y}_{j}^{\text {test }}\right| / \boldsymbol{y}_{j}^{\text {test }} \\
\hat{\mu}=\frac{1}{k} \sum_{i=1}^{k} \hat{\mu}_{i}
\end{gathered}
$$

\subsection{Results and Discussion}

First, all available static measurements and dynamic measurements are used to perform identification. For the dynamic part, the modal assurance criterion is calculated to ensure the same mode is compared. Then, the natural frequencies are used to perform model falsification. Candidate model sets $\left(C M S_{s}^{k}\right.$ and $\left.C M S_{d}^{k}\right)$ are obtained using static and dynamic measurements separately in the $k$ th iteration. The identified parameter values are shown in Figure 8. The identified $E$ values vary from $39,800 \mathrm{MPa}$ to 42,000 $\mathrm{MPa}$ in $C M S_{S}^{1}$ and from 26,740 to $29,900 \mathrm{MPa}$ in $C M S_{d}^{1}$. The distance $d_{E}^{1}$ between the two ranges is $9,900 \mathrm{MPa}$, which is $45 \%$ of the whole range of $R_{E}$. This already exceeds the threshold $\alpha=10 \%$ implying the existence of abnormal measurements. Then, we investigated the falsification capability of each static measurement and found that $\mathrm{S}_{8}$ falsifies the biggest portion of $C M S_{d}^{1}$. Thus $\mathrm{S}_{8}$ is removed from the measurement set.

A new model falsification is carried out based on the new measurement sets. The identified $E$ values range from $34,400 \mathrm{MPa}$ to $42,000 \mathrm{MPa}$ in $C M S_{S}^{2}$. The distance $d_{E}^{2}$ between two ranges is $4,500 \mathrm{MPa}$, which is $20 \%$ of the whole range $R_{E}$. This value also 
1 exceeds $\alpha$. Following the same procedure of the previous iteration, $\mathrm{S} 2$ is removed from

2 the measurement set.

3 In the following iterations, S7, S3, S4, S6 are removed from the static 4 measurement set in a sequence. The quality of these sensor signals was likely 5 compromised by the installation process due to inexperienced workers as mentioned 6 earlier.

7 In the last iteration, the ranges of $\boldsymbol{\theta}_{E, s}$ and $\boldsymbol{\theta}_{E, d}$ overlap (as shown in Figure 9).

8 The identified sets of parameter $\mathrm{E}$ in each iteration is shown in Figure 9. The dots 9 indicate the identified parameter values using static measurements $\theta_{E, s}$ and the small 10 circles represent the ones obtained using dynamic measurements $\theta_{E, d}$. After the last 11 iteration, the remaining static measurements are $\mathrm{P} 1, \mathrm{P} 2, \mathrm{P} 3, \mathrm{P} 4, \mathrm{~S} 1, \mathrm{~S} 5, \mathrm{In} 1, \mathrm{In} 2$,

Following our methodology, all selected static and dynamic measurements should 13 be combined together to determine the candidate models. To study the effects of using 14 both types of data, we create three different scenarios. In Scenario I, the information 15 provided by dynamic measurements are used, which falsify $6,210,000$ model instances 16 and lead to 40,000 candidate model instances. In Scenario II, static measurements (after 17 removing abnormal measurements) are used and 6,138,751 model instances are 18 falsified leading to 111,249 candidate model instances. In Scenario III, both static and 19 dynamic measurements are used, which falsify the largest number $(6,248,881)$ of model 20 instances leading to 1,119 candidate model instances. The results show that the 21 falsification capability is greatly enhanced by using both static and dynamic 22 measurements. 98.99\% candidate model instance in Scenario II are falsified by 23 introducing dynamic measurements. The identified range of parameters by using both measurements is shown in Figure 25 10. The vertical axes represent parameter values and predictions of static data and 
1 dynamic data. Each grey line represents a candidate model instance. The red dashed

2 lines represent the threshold boundaries calculated for each response. Arrows represent

3 the corresponding measured values.

\section{Conclusions}

In this paper, an approach based on model falsification is proposed to combine both static and dynamic measurements with explicit representation of both modeling and measurement uncertainties. A measurement selection strategy is also presented to detect abnormal measurements that need to be excluded from the falsification framework.

1. This approach has been successfully applied to a highway flyover bridge in Singapore. The measurement selection strategy eliminates six abnormal strain data in a systematic and progressive way. The identification results have been improved significantly by using both static and dynamic measurements. Specifically, in this case study, dynamic measurements help further falsify $98.99 \%$ of the candidate models obtained using only static measurements.

2. The proposed measurement selection strategy would help asset managers to locate possible abnormal sensors and make adjustments to sensor installation if needed. Not being limited to the application presented in the case study (using dynamic measurements to detect abnormal strain data), this strategy also applies to subsets of experiment data, i.e. to use high-quality measurement data to detect abnormal low-quality measurement data.

3. The proposed framework incorporates the use of surrogate models and associated uncertainty quantification. It enables efficient execution of the identification process. In the case study, only 1,000 FEM analyses are carried out to support $6,250,000$ simulations using surrogate models. 
As a multiple-model approach, the output of the identification process is a set of

2 parameter ranges. They are considered acceptable due to the presence of uncertainties.

3 Future work will focus on determining efficient ways to employ the candidate models

4 for prediction.

5

\section{Acknowledgements}

This research was conducted at the Future Cities Laboratory at the Singapore-ETH Center (SEC). The SEC was established as a collaboration between ETH Zurich and National Research Foundation (NRF) Singapore (FI 370074016) under the auspices of the NRF's Campus for Research Excellence and Technological Enterprise (CREATE) programme. The authors would like to gratefully acknowledge the support of the Land Transport Authority of Singapore (LTA) to perform the case study. Any opinions, findings, and conclusions or recommendations expressed in this paper are those of the authors and do not reflect the views of the Land Transport Authority of Singapore.

\section{References}

1. Araujo IG, Maldonado E, Cho GC. Ambient vibration testing and updating of the finite element model of a simply supported beam bridge. Frontiers of Architecture and Civil Engineering in China. 2011;5(3):344.

2. Wan HP, Ren WX. A residual-based Gaussian process model framework for finite element model updating. Computers \& Structures. 2015;156:149-59.

3. Jafarkhani R, Masri SF. Finite element model updating using evolutionary strategy for damage detection. Computer-Aided Civil and Infrastructure Engineering. 2011;26(3):207-24.

4. Okasha NM, Frangopol DM, Orcesi AD. Automated finite element updating using strain data for the lifetime reliability assessment of bridges. Reliability Engineering \& System Safety. 2012;99:139-50.

5. Yuen KV, Beck JL, Katafygiotis LS. Efficient model updating and health monitoring methodology using incomplete modal data without mode matching. 
Structural Control and Health Monitoring. 2006;13(1):91-107.

6. Cheung SH, Beck JL. Calculation of posterior probabilities for Bayesian model class assessment and averaging from posterior samples based on dynamic system data. Computer-Aided Civil and Infrastructure Engineering. 2010;25(5):304-21.

7. Beck JL, Katafygiotis LS. Updating models and their uncertainties. I: Bayesian statistical framework. Journal of Engineering Mechanics. 1998;124(4):455-61.

8. Goller B, Schueller GI. Investigation of model uncertainties in Bayesian structural model updating. Journal of sound and vibration. 2011;330(25):6122-36.

9. Goulet JA, Smith IFC. Structural identification with systematic errors and unknown uncertainty dependencies. Computers \& structures. 2013;128:251-8.

10. Popper K. The logic of scientific discovery. Routledge; 2005.

11. Raphael B, Smith IFC. Finding the right model for bridge diagnosis. In Artificial intelligence in structural engineering 1998 (pp. 308-319). Springer, Berlin, Heidelberg.

12. Robert-Nicoud Y, Raphael B, Smith IFC. System identification through model composition and stochastic search. Journal of computing in civil engineering. 2005;19(3):239-47.

13. Goulet JA, Kripakaran P, Smith IFC. Multimodel structural performance monitoring. Journal of structural engineering. 2010;136(10):1309-18.

14. Pasquier R, Goulet JA, Acevedo C, Smith IFC. Improving fatigue evaluations of structures using in-service behavior measurement data. Journal of Bridge Engineering. 2014;19(11):04014045.

15. Goulet JA, Texier M, Michel C, Smith IFC, Chouinard L. Quantifying the effects of modeling simplifications for structural identification of bridges. Journal of Bridge Engineering. 2013;19(1):59-71.

16. Vernay DG, Raphael B, Smith IFC. Improving simulation predictions of wind around buildings using measurements through system identification techniques. Building and Environment. 2015;94:620-31.

17. Papadopoulou M, Raphael B, Smith IFC, Sekhar C. Optimal sensor placement for time-dependent systems: Application to wind studies around buildings. Journal of Computing in Civil Engineering. 2015;30(2):04015024.

18. Moser G, Paal SG, Smith IFC. Leak Detection of Water Supply Networks Using Error-Domain Model Falsification. Journal of Computing in Civil 
Engineering. 2017;32(2):04017077.

19. Mottershead JE, Friswell MI. Model updating in structural dynamics: a survey. Journal of sound and vibration. 1993;167(2):347-75.

20. Wan HP, Mao Z, Todd MD, Ren WX. Analytical uncertainty quantification for modal frequencies with structural parameter uncertainty using a Gaussian process metamodel. Engineering Structures. 2014;75:577-89.

21. Koh CG, See LM, Balendra T. Estimation of structural parameters in time domain: a substructure approach. Earthquake Engineering \& Structural Dynamics. 1991;20(8):787-801.

22. Salawu OS. Detection of structural damage through changes in frequency: a review . Engineering Structures.1997;19:718-23.

23. Teughels A, De Roeck G. Structural damage identification of the highway bridge Z24 by FE model updating. Journal of Sound and Vibration. 2004;278(3):589-610.

24. Simoen E, De Roeck G, Lombaert G. Dealing with uncertainty in model updating for damage assessment: A review. Mechanical Systems and Signal Processing. 2015;56:123-49.

25. Xu ZD, Wu Z. Energy Damage detection strategy based on acceleration responses for long-span bridge structures, Engineering Structures, 2007, 29(4):609617.

26. Xu ZD, Liu M, Wu Z, Zeng, X. Energy damage detection strategy based on strain responses for long-span bridge structures, Journal of Bridge Engineering, ASCE, 2011, 16(5):162-171.

27. Brownjohn JM, Moyo P, Omenzetter P, Lu Y. Assessment of highway bridge upgrading by dynamic testing and finite-element model updating. Journal of Bridge Engineering. 2003;8(3):162-72.

28. Zárate BA, Caicedo JM. Finite element model updating: Multiple alternatives. Engineering Structures 2008;30:3724-30.

29. Ren WX, Chen HB. Finite element model updating in structural dynamics by using the response surface method. Engineering Structures 2010;32.

30. Gentile C, Gallino N. Ambient vibration testing and structural evaluation of an historic suspension footbridge. Advances in Engineering Software. 2008;39(4):356-66.

31. Liu C, DeWolf JT, Kim JH. Development of a baseline for structural health monitoring for a curved post-tensioned concrete box-girder bridge. Engineering 
Structures. 2009;31(12):3107-15.

32. Ni YC, Zhang FL, Lam HF. Series of full-scale field vibration tests and Bayesian modal identification of a pedestrian bridge. Journal of Bridge Engineering. 2016;21(8):C4016002.

33. De Sortis A, Antonacci E, Vestroni F. Dynamic identification of a masonry building using forced vibration tests. Engineering Structures. 2005;27(2):155-65.

34. Ren WX, Fang SE, Deng MY. Response surface-based finite-elementmodel updating using structural static responses. Journal of Engineering Mechanics. 2010;137(4):248-57.

35. Sanayei M, Khaloo A, Gul M, Catbas FN. Automated finite element model updating of a scale bridge model using measured static and modal test data. Engineering Structures. 2015;102:66-79.

36. Schlune H, Plos M, Gylltoft K. Improved bridge evaluation through finite element model updating using static and dynamic measurements. Engineering structures. 2009;31(7):1477-85.

37. Goller B, Beck JL, Schueller GI. Evidence-based identification of weighting factors in Bayesian model updating using modal data. Journal of Engineering Mechanics. 2011;138(5):430-40.

38. Pasquier R, Smith IFC. Iterative structural identification framework for evaluation of existing structures. Engineering structures. 2016;106:179-94.

39. Aggarwal CC. Outlier analysis. In Data mining 2015 (pp. 237-263). Springer, Cham.

40. ANSYS, IC. User's manual 17.0. Pennsylvania: ANSYS 2016.

41. Saltelli A, Ratto M, Andres T, Campolongo F, Cariboni J, Gatelli D, Saisana M, Tarantola S. Global sensitivity analysis: the primer. John Wiley \& Sons; 2008.

42. McKay M. Latin hypercube sampling as a tool in uncertainty analysis of computer models . Proceedings of the 24th conference on winter simulation 1992; 129815: 557-564.

43. Proverbio M, Costa A, Smith IFC. Adaptive Sampling Methodology for Structural Identification Using Radial-Basis Functions. Journal of Computing in Civil Engineering. 2018;32(3):04018008. 
$>$ Table 1: Details of dynamic tests

3

Table 2: Identified natural frequencies using free vibrations

4

Table 3: Operational modal analysis results

5

Table 4: Parameter initial ranges

6

Table 5: Uncertainty sources of static measurements

7

Table 6: Uncertainty sources of dynamic measurements

8

Table 7: Surrogate model uncertainties

9

10 
2

3

4 6

Figure 1: Flowchart of system identification using both static and dynamic measurements

$>$ Figure 2: Photos of the highway flyover (image credit: FCL-CCI)

$>$ Figure 3: Sensor configuration and truck configuration in the static test:

(a) top view; (b) bottom view

$>$ Figure 4: Dynamic test 2 (a) field test photo, (b) signal recorded by C1, (c) FFT result; Dynamic test 5 (d) field test photo, (e) signal recorded by A1, (f) FFT result.

$>$ Figure 5: Stabilization diagrams (SSI-UPC)

Figure 6: Finite element model of the bridge

Figure 7: Parameter sensitivity results

$>$ Figure 8: Parameter values of $\mathrm{CMS}_{\mathrm{s}}^{1}$ and $\mathrm{CMS}_{\mathrm{d}}^{1}$. Each vertical axis represents a parameter.

Figure 9 : Identified $\mathrm{E}$ values by $\mathrm{CMS}_{\mathrm{s}}$ and $\mathrm{CMS}_{\mathrm{d}}$ during each iteration

5 Figure 10: Identified parameter sets using both static and dynamic measurements 
Table 1: Details of dynamic tests

\begin{tabular}{ccccccccc}
\hline Test No. & 1 & 2 & 3 & 4 & 5 & 6 & 7 & 8 \\
\hline Vehicle numbers & 1 & 1 & 1 & 2 & 1 & 1 & 2 & 1 \\
\hline Speed & slow & slow & fast & slow & slow & slow & slow & fast \\
\hline Lane & 2 & 3 & 2 & 3 & 2 & 3 & 2 & 3 \\
\hline Hump & & & & yes & yes & & \\
\hline
\end{tabular}

2

3

4

Table 2: Identified natural frequencies using free vibrations

\begin{tabular}{ccccc}
\hline & Mode 1 & Mode 2 & Mode 3 & Mode 4 \\
\hline Natural frequency $(\mathrm{Hz})$ & 4.0 & 6.1 & 10.1 & 14.8 \\
\hline
\end{tabular}

6

7

8

9

Table 3: Operational modal analysis results

\begin{tabular}{lllll}
\hline & Mode 1 & Mode 2 & Mode 3 & Mode 4 \\
\hline $\begin{array}{c}\text { Mode } \\
\text { Shape }\end{array}$ & & & & \\
\hline Frequency & $3.982 \mathrm{~Hz}$ & $6.128 \mathrm{~Hz}$ & $9.929 \mathrm{~Hz}$ & $14.567 \mathrm{~Hz}$ \\
\hline $\begin{array}{c}\text { Std. } \\
\text { Frequency }\end{array}$ & $0.012 \mathrm{~Hz}$ & $0.011 \mathrm{~Hz}$ & $0.008 \mathrm{~Hz}$ & $0.002 \mathrm{~Hz}$ \\
\hline
\end{tabular}

10

11 
Table 4: Parameter initial ranges

\begin{tabular}{c|c|c|c|c}
\hline Parameter & Description & $\begin{array}{c}\text { Lower } \\
\text { bound }\end{array}$ & $\begin{array}{c}\text { Upper } \\
\text { bound }\end{array}$ & $\begin{array}{c}\text { Sensitivity } \\
\text { analysis } \\
\text { results }\end{array}$ \\
\hline$E(\mathrm{MPa})$ & Young's modulus of concrete & 20,000 & 40,000 & keep \\
\hline$D\left(\mathrm{~kg} / \mathrm{m}^{3}\right)$ & Density of the bridge & 1800 & 3000 & keep \\
\hline $\begin{array}{c}\mathrm{LogB} \\
(\mathrm{Nmm} / \mathrm{rad})\end{array}$ & $\begin{array}{c}\log \text { of the bending stiffness } \\
\text { of bearing }\end{array}$ & 9 & 13 & keep \\
\hline \begin{tabular}{c}
$\mathrm{LogV}(\mathrm{N} / \mathrm{mm})$ \\
\hline $\log$ of the vertical stiffness of \\
bearing
\end{tabular} & 8 & 11 & keep \\
\hline $\operatorname{LogL}(\mathrm{N} / \mathrm{mm})$ & $\begin{array}{c}\text { log of the longitudinal } \\
\text { stiffness of bearing }\end{array}$ & 9 & 11 & delete \\
\hline
\end{tabular}

2

3 
Table 5: Uncertainty sources of static measurements

\begin{tabular}{|c|c|c|c|c|c|c|c|}
\hline \multirow{2}{*}{\multicolumn{2}{|c|}{ Uncertainty source }} & \multicolumn{2}{|c|}{$\begin{array}{l}\text { Displacement } \\
\text { (P1 P4) }\end{array}$} & \multicolumn{2}{|c|}{$\begin{array}{l}\text { Rotations } \\
\text { (In1 In2) }\end{array}$} & \multicolumn{2}{|c|}{$\begin{array}{l}\text { Strains } \\
(\mathrm{S} 1 \sim \mathrm{S} 8)\end{array}$} \\
\hline & & Min & Max & Min & $\operatorname{Max}$ & Min & Max \\
\hline \multirow{5}{*}{$\begin{array}{c}\text { Modeling } \\
\text { uncertainties }\end{array}$} & $\begin{array}{c}\text { Model } \\
\text { simplifications } \\
\text { and FE } \\
\text { method (\%) }\end{array}$ & -5 & 13 & -5 & 13 & -5 & 13 \\
\hline & $\begin{array}{l}\text { Mesh } \\
\text { refinement } \\
(\%)\end{array}$ & -1 & 1 & -1 & 1 & -1 & 1 \\
\hline & $\begin{array}{c}\text { Spatial } \\
\text { variability }(\%)\end{array}$ & - & - & - & - & -5 & 5 \\
\hline & $\begin{array}{c}\text { Additional } \\
\text { uncertainty } \\
(\%)\end{array}$ & -1 & 1 & -1 & 1 & -1 & 1 \\
\hline & $\begin{array}{l}\text { Surrogate } \\
\text { model } \\
\text { uncertainty } \\
(\%)\end{array}$ & \multicolumn{6}{|c|}{ Shown in Table 7} \\
\hline \multirow{4}{*}{$\begin{array}{l}\text { Measurement } \\
\text { uncertainties }\end{array}$} & $\begin{array}{l}\text { Sensor } \\
\text { accuracy }\end{array}$ & $-0.05 \mathrm{~mm}$ & $0.05 \mathrm{~mm}$ & $\stackrel{-}{\mu \mathrm{rad}}$ & $1 \mu \mathrm{rad}$ & $2 \overline{\mu \epsilon}$ & $2 \mu \epsilon$ \\
\hline & Repeatability & $-0.15 \mathrm{~mm}$ & $0.15 \mathrm{~mm}$ & $\stackrel{-}{4 \mu \mathrm{rad}}$ & $4 \mu \mathrm{rad}$ & $4 \overline{\mu \epsilon}$ & $4 \boldsymbol{\mu} \epsilon$ \\
\hline & $\begin{array}{c}\text { Sensor } \\
\text { orientation } \\
(\%)\end{array}$ & - & - & - & - & 0 & 6 \\
\hline & $\begin{array}{c}\text { Sensor } \\
\text { installation } \\
(\%)\end{array}$ & - & - & -5 & 5 & 0 & 5 \\
\hline
\end{tabular}


Table 6: Uncertainty sources of dynamic measurements

\begin{tabular}{|c|c|c|c|c|c|}
\hline \multicolumn{2}{|c|}{ Uncertainty source } & \multicolumn{4}{|c|}{ Measured frequency $(\mathrm{Hz})$} \\
\hline & & 4.0 & 6.1 & 10.057 & 14.732 \\
\hline & & $f_{1}$ & $f_{2}$ & $f_{3}$ & $f_{4}$ \\
\hline \multirow{4}{*}{$\begin{array}{c}\text { Modeling } \\
\text { uncertainties }\end{array}$} & $\begin{array}{c}\text { Model } \\
\text { simplifications } \\
\text { and FE } \\
\text { method }(\%)\end{array}$ & {$[-8,5]$} & {$[-8,5]$} & {$[-8,5]$} & {$[-8,5]$} \\
\hline & $\begin{array}{l}\text { Mesh } \\
\text { refinement } \\
(\%)\end{array}$ & {$[0,2]$} & {$[0,2]$} & {$[0,2]$} & {$[0,2]$} \\
\hline & $\begin{array}{c}\text { Additional } \\
\text { uncertainty } \\
(\%)\end{array}$ & {$[-1,1]$} & {$[-1,1]$} & {$[-1,1]$} & {$[-1,1]$} \\
\hline & $\begin{array}{l}\text { Surrogate } \\
\text { model } \\
\text { uncertainty }\end{array}$ & \multicolumn{4}{|c|}{ Shown in Table 7} \\
\hline \multirow{2}{*}{$\begin{array}{l}\text { Measurement } \\
\text { uncertainties }\end{array}$} & $\begin{array}{c}\text { Modal } \\
\text { analysis } \\
\text { results }(\mathrm{Hz})\end{array}$ & $\begin{array}{c}{[-0.1} \\
0.1]\end{array}$ & $\begin{array}{c}{[-0.1} \\
0.1]\end{array}$ & $\begin{array}{l}{[-} \\
0.144,0.144]\end{array}$ & $\begin{array}{c}{[-} \\
0.169,0.169]\end{array}$ \\
\hline & $\begin{array}{c}\text { Additional } \\
\text { uncertainty } \\
(\%)\end{array}$ & {$[-1,1]$} & {$[-1,1]$} & {$[-1,1]$} & {$[-1,1]$} \\
\hline
\end{tabular}

2

3 
Table 7: Surrogate model uncertainties

\begin{tabular}{|c|c|c|c|c|}
\hline \multirow{10}{*}{$\begin{array}{c}\text { Surrogate } \\
\text { model } \\
\text { uncertainties } \\
\text { Min/ Max (\%) }\end{array}$} & $f_{1}$ & $f_{2}$ & $f_{3}$ & $f_{4}$ \\
\hline & $\mp 0.012$ & $\mp 0.011$ & $\mp 0.012$ & $\mp 0.026$ \\
\hline & $\mathrm{P} 1$ & $\mathrm{P} 2$ & P3 & P4 \\
\hline & $\mp 0.3$ & $\mp 0.65$ & $\mp 0.25$ & $\mp 0.33$ \\
\hline & S1 & $\mathrm{S} 2$ & S3 & S4 \\
\hline & $\mp 0.26$ & $\mp 0.24$ & $\mp 0.25$ & $\mp 0.22$ \\
\hline & S5 & S6 & S7 & S8 \\
\hline & $\mp 0.22$ & $\mp 0.22$ & $\mp 0.24$ & $\mp 0.3$ \\
\hline & In 1 & In 2 & & \\
\hline & $\mp 0.33$ & $\mp 0.59$ & & \\
\hline
\end{tabular}

2

3 


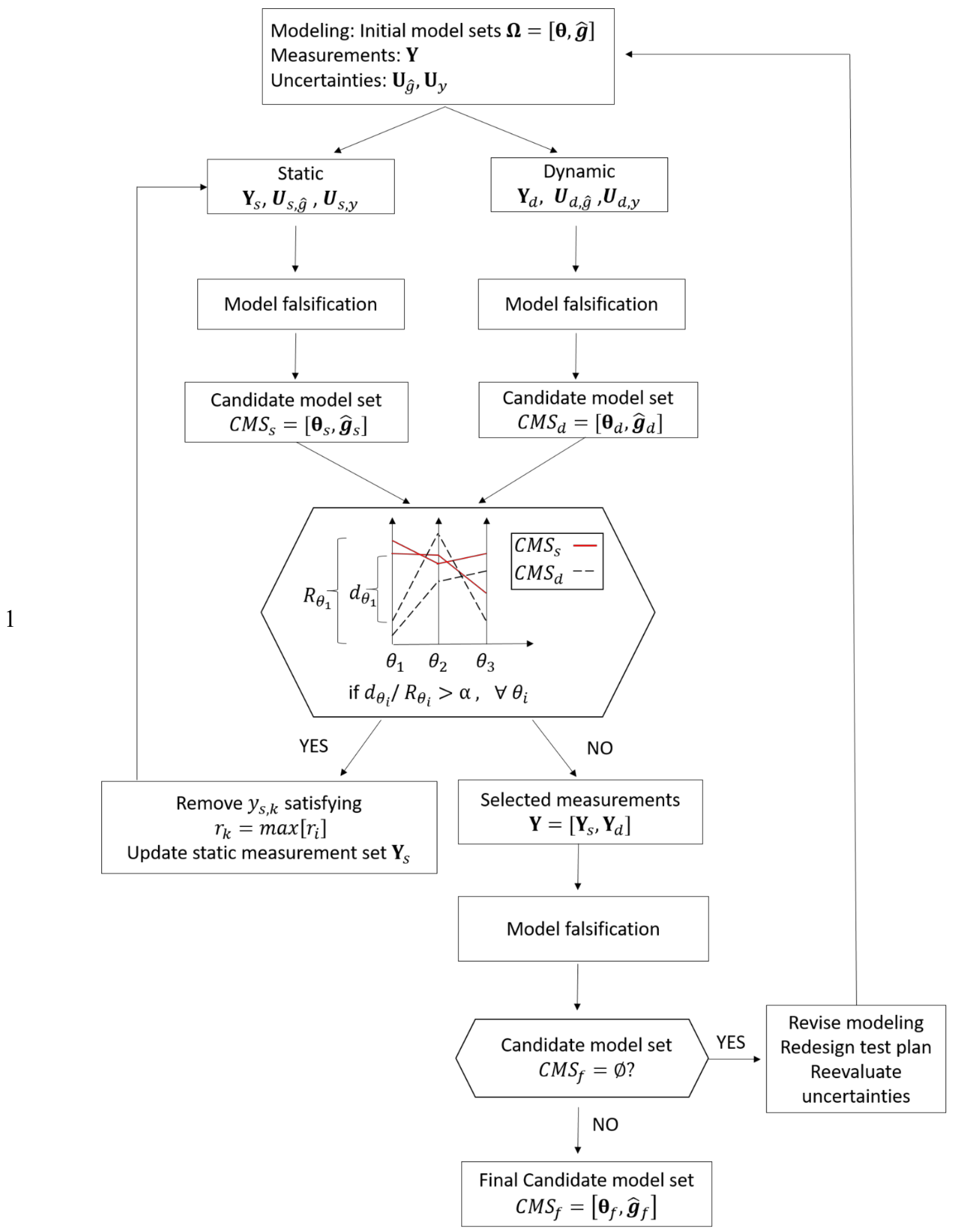

2 Figure 1: Flowchart of system identification using both static and dynamic 3 measurements 


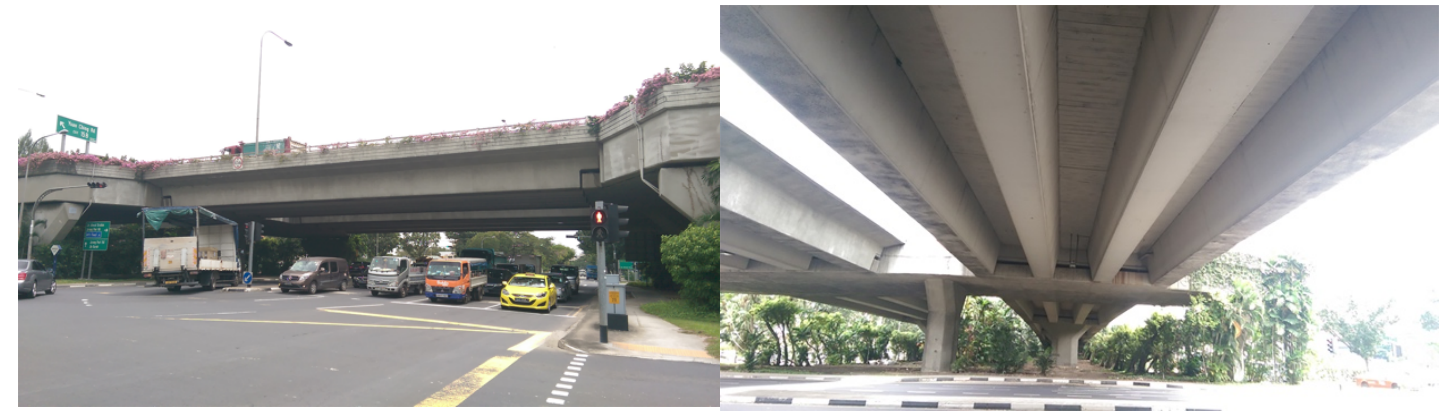

2

Figure 2: Photos of the highway flyover (image credit: FCL-CCI)

3

4

5

6

7

8

9

10

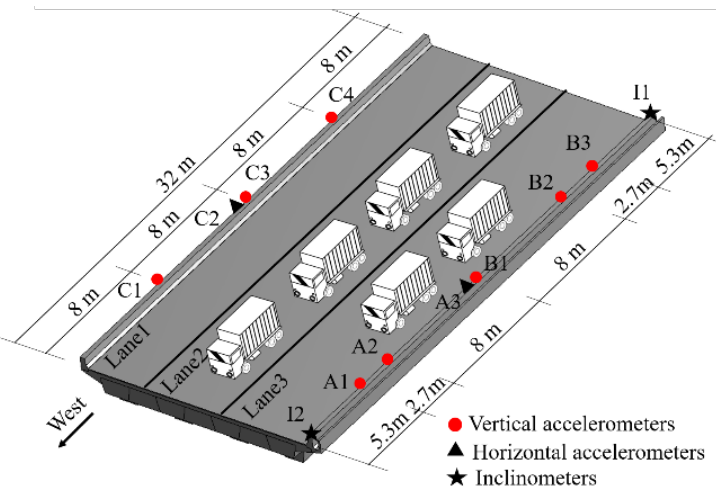

(a)

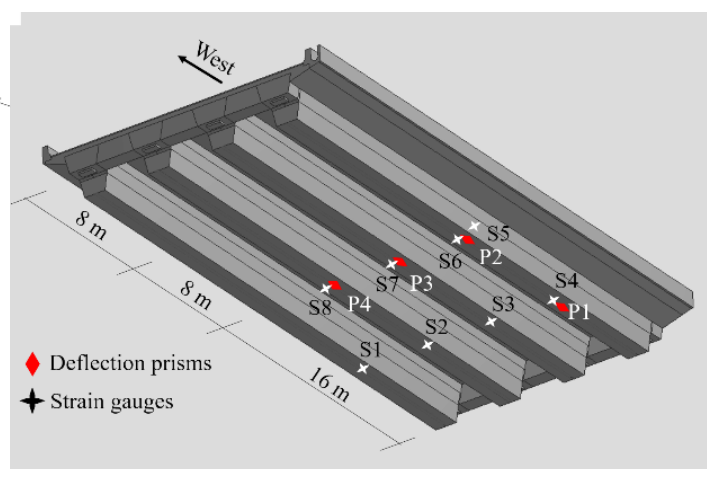

(b)

Figure 3: Sensor configuration and truck configuration in the static test:

(a) top view; (b) bottom view 


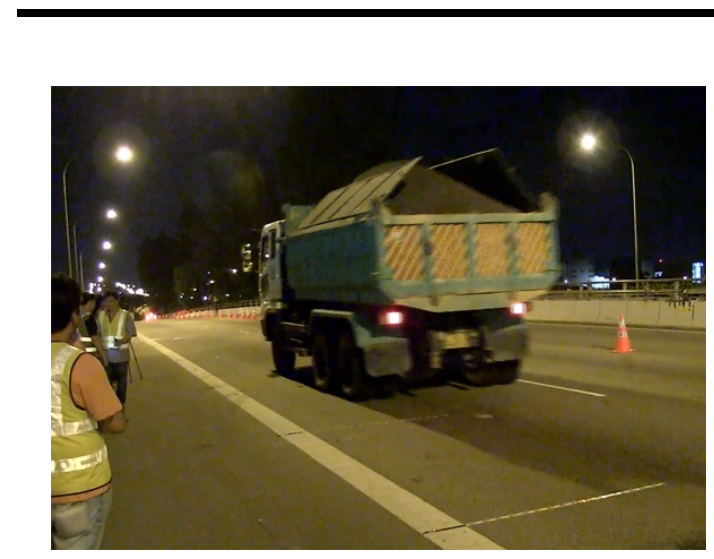

(a)

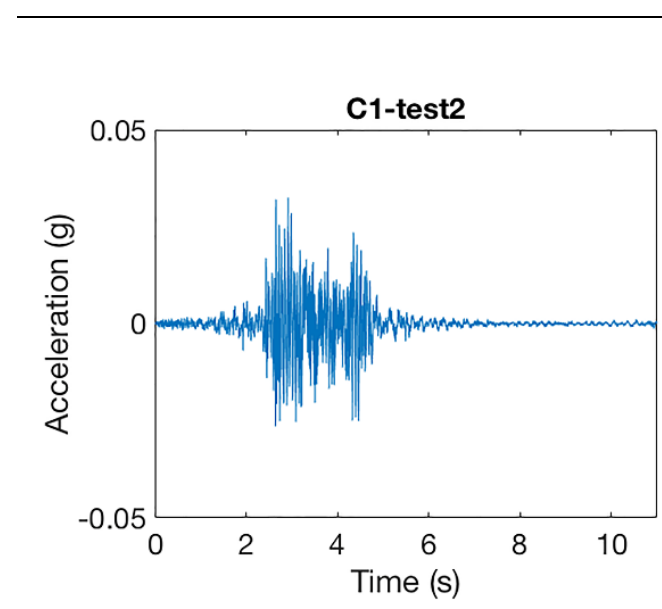

(b)

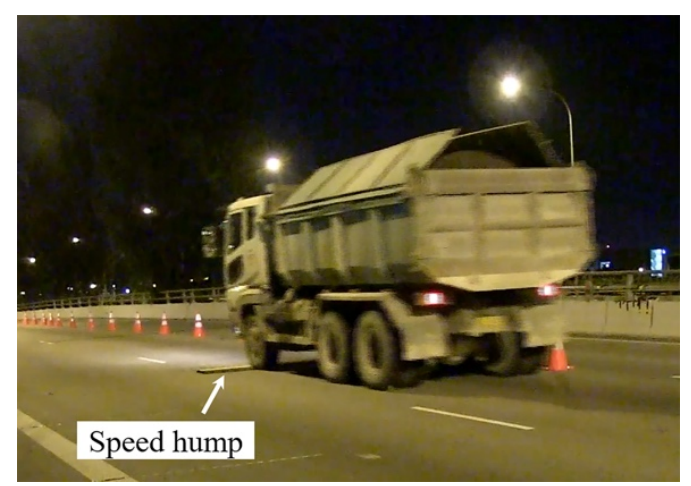

(d)

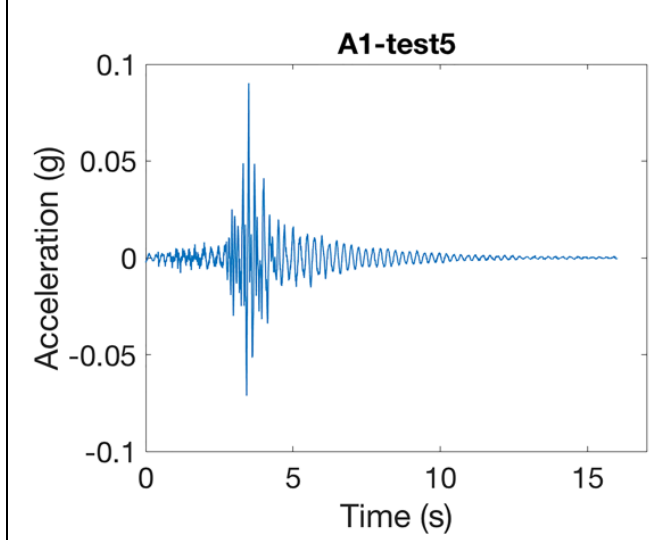

(e)

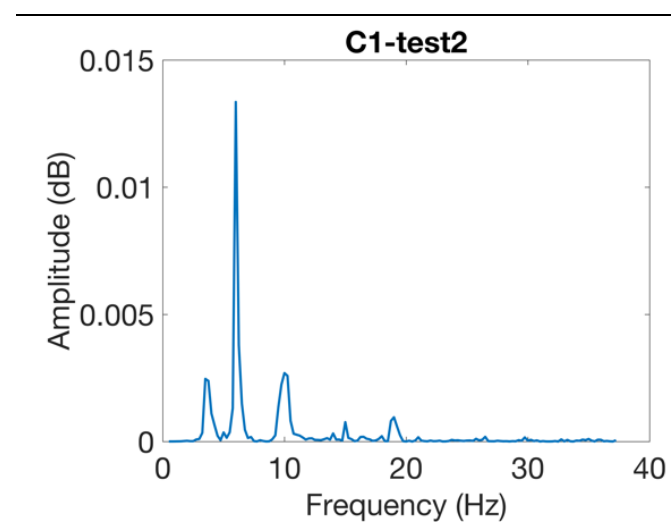

(c)

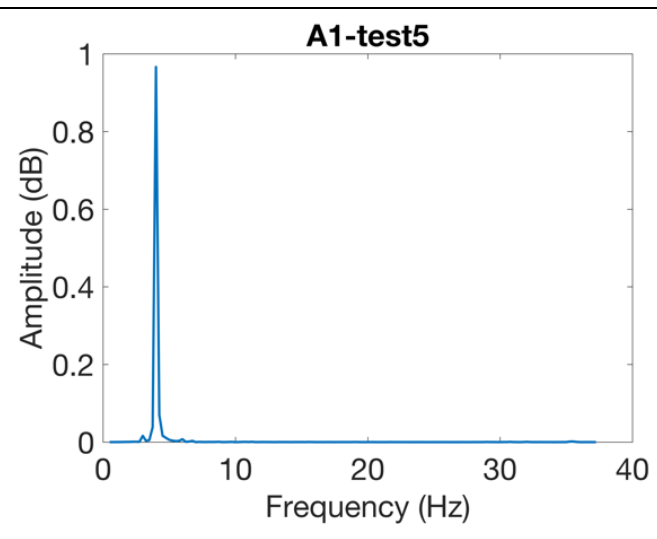

(f)

Figure 4: Dynamic test 2: (a) field test photo, (b) signal recorded by C1, (c) FFT

2 result; Dynamic test 5: (d) field test photo, (e) signal recorded by A1, (f) FFT result. 


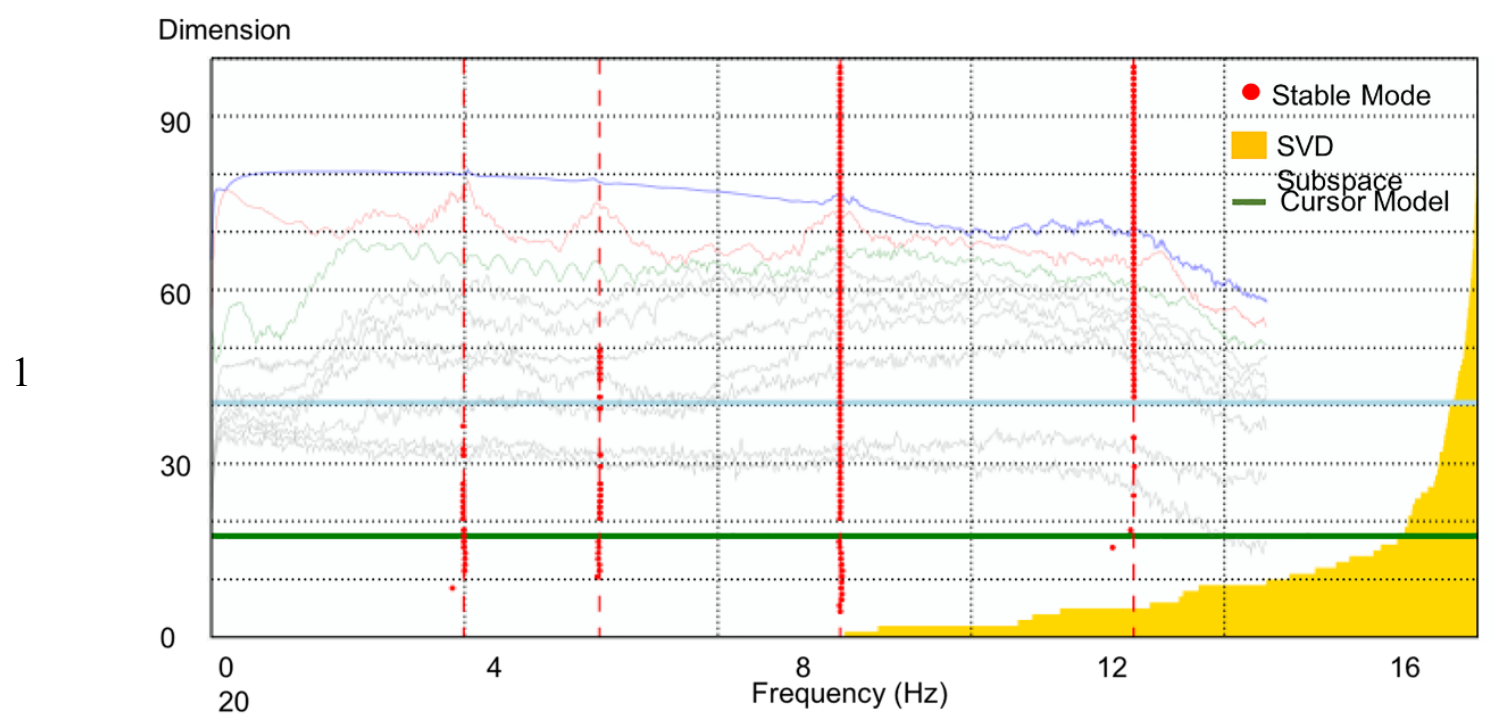

Figure 5: Stabilization diagrams (SSI-UPC)

3

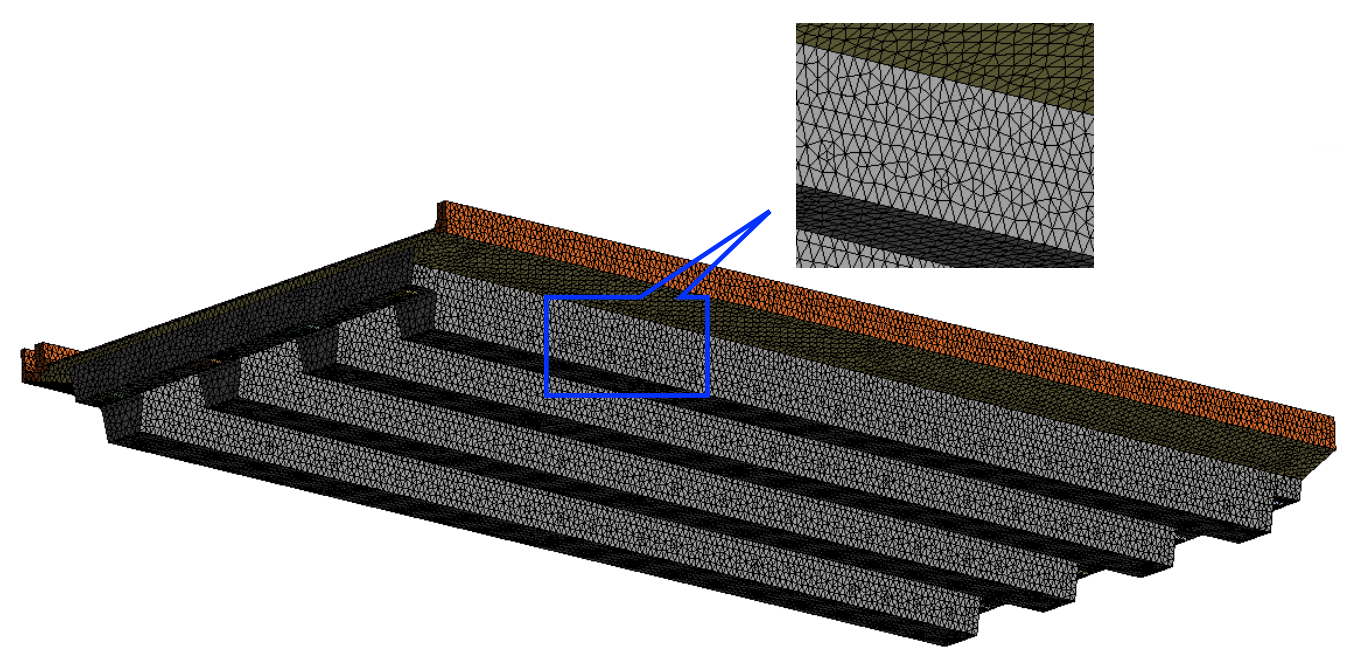

Figure 6: Finite element model of the bridge 


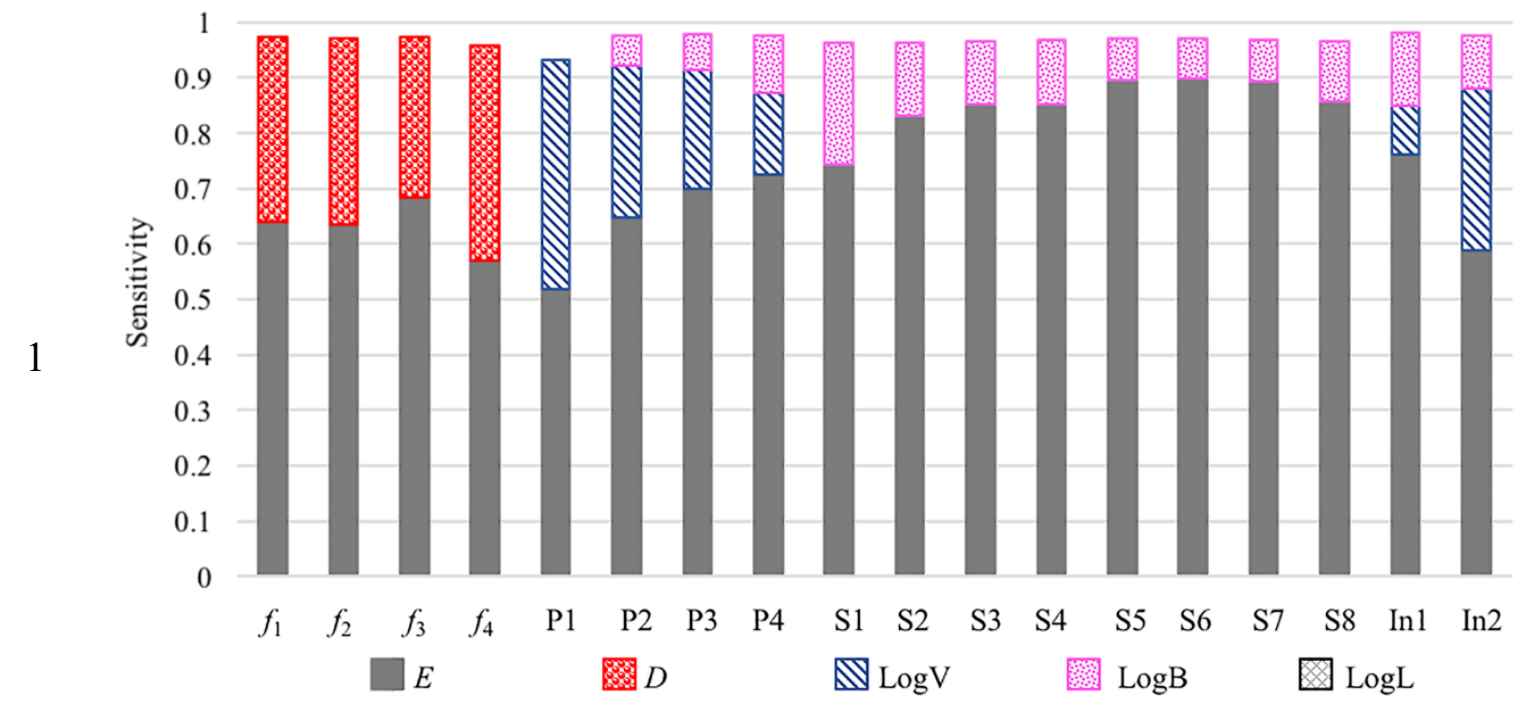

Figure 7: Parameter sensitivity results

3 
1

2

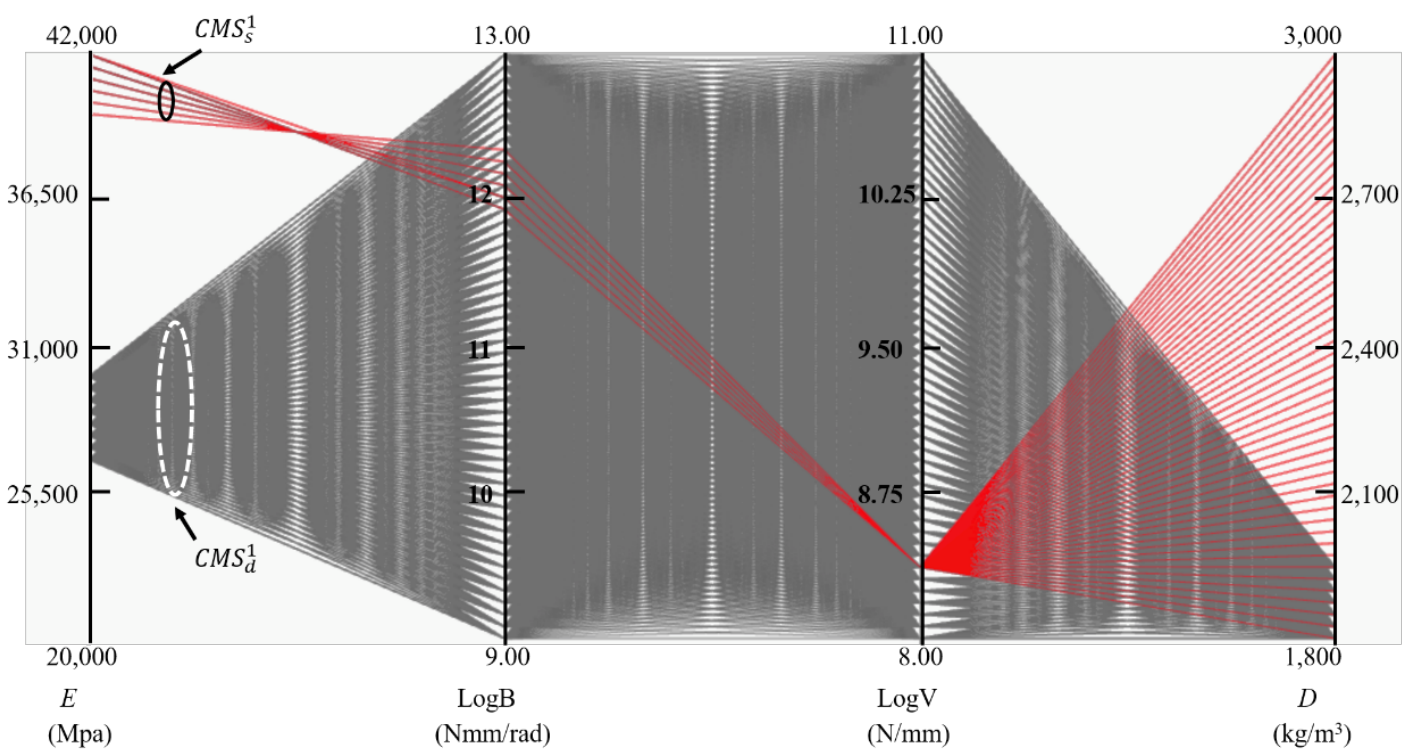

Figure 8: Parameter values of $C M S_{s}^{1}$ and $C M S_{d}^{1}$. Each vertical axis represents a parameter.

5

6

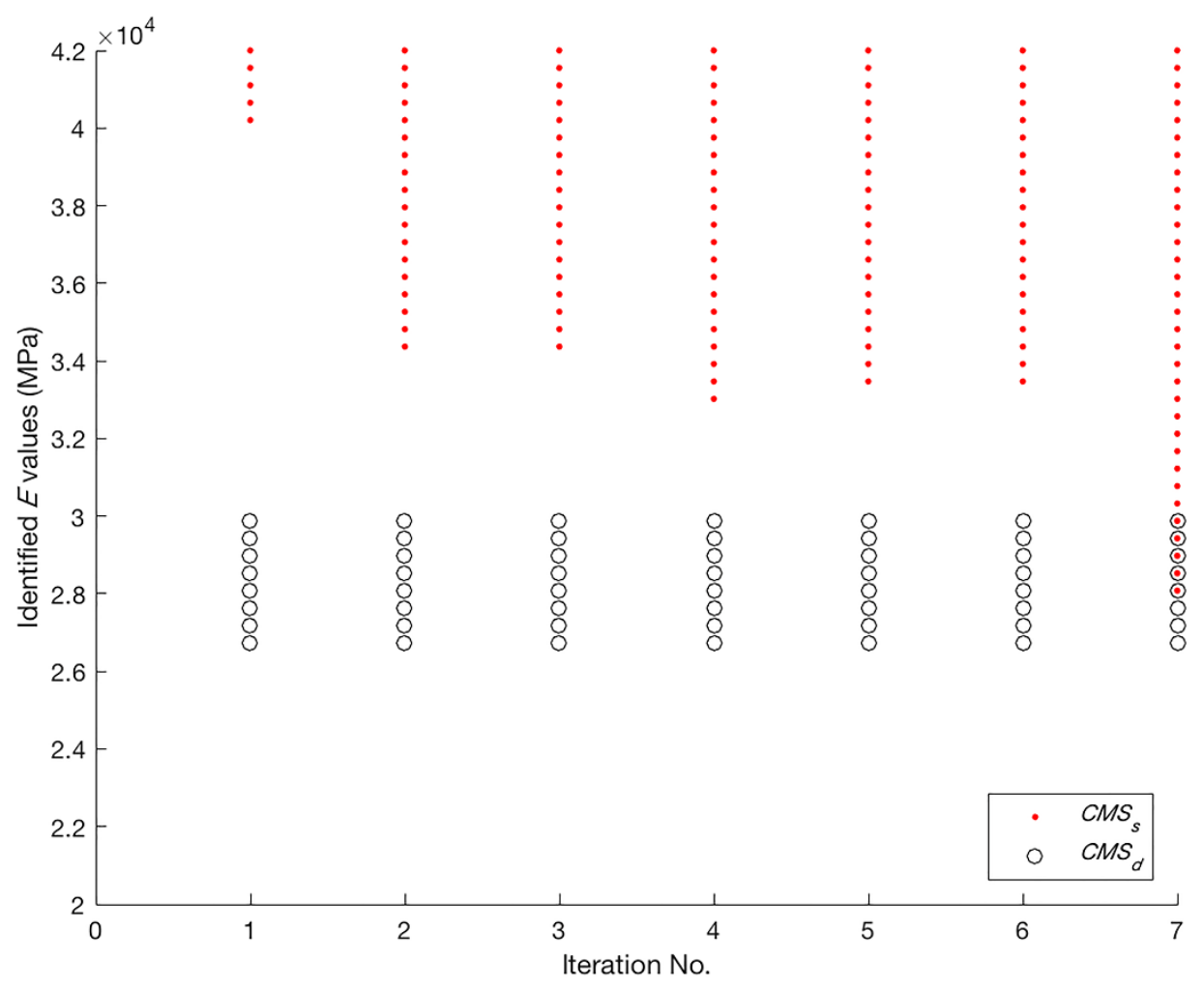

Figure 9: Identified $E$ values by $C M S_{S}$ and $C M S_{d}$ during each iteration 


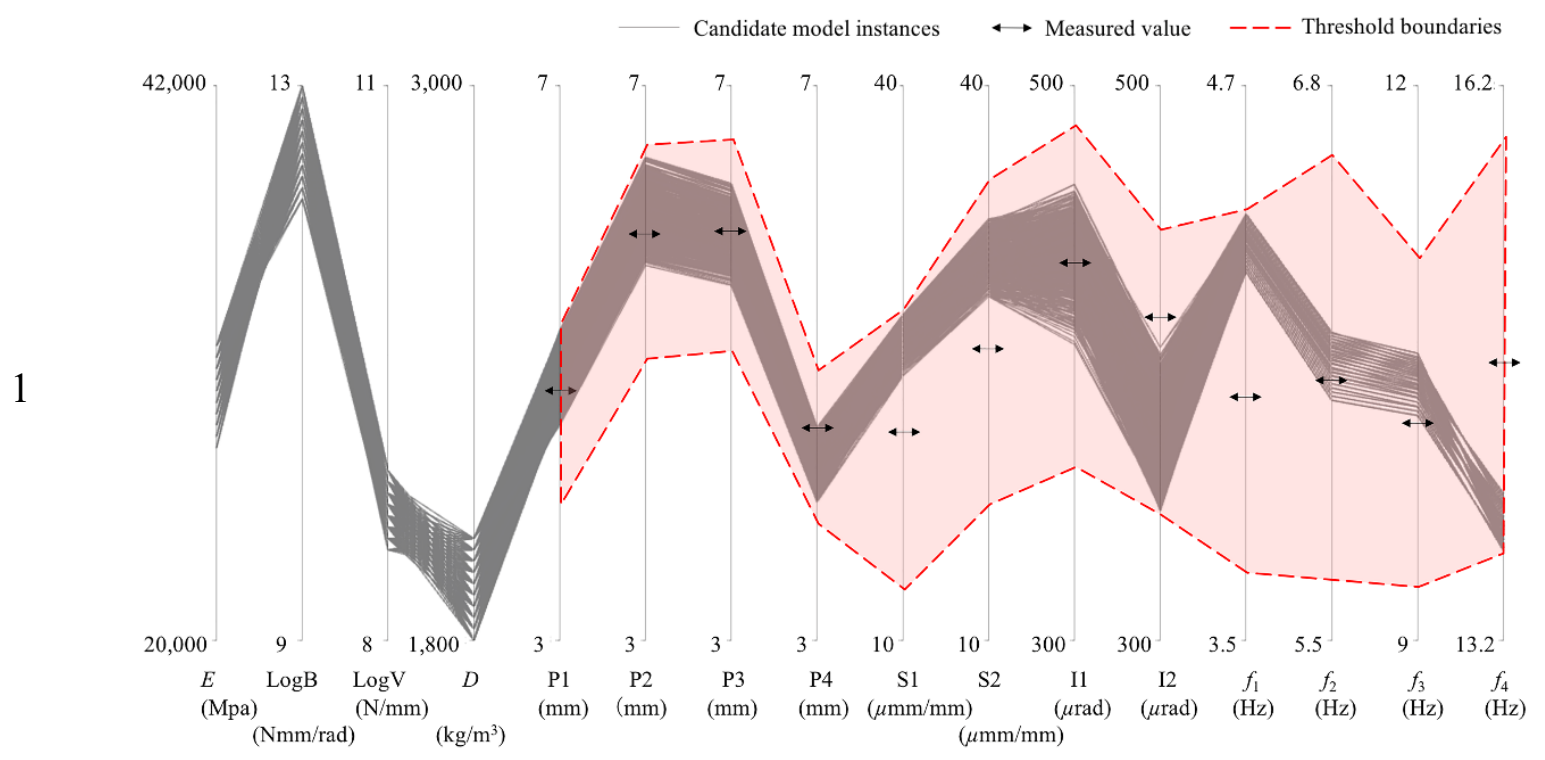

Figure 10: Identified parameter sets using both static and dynamic measurements

This work is licensed under a Creative Commons Attribution-Non-Commercial-No-Derivatives 4.0 International License

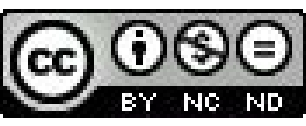

